Journal of Pharmacy Practice and Community Medicine.2018, 4(1s):S103-S108 • http://dx.doi.org/10.5530/jppcm.2018.1s.30

e-ISSN: 2455-3255

\title{
Hospital Pharmacist Workforce Analysis in Eleven-Year 2006-2016 at Healthcare Institutions in Saudi Arabia
}

\author{
Yousef Ahmed Alomi ${ }^{*}$, Saeed Jamaan Alghamdi², Radi Abdullah Alattyh ${ }^{2}$ \\ ${ }^{1}$ The Past General Manager of General Administration of Pharmaceutical Care and The Past Head, National Clinical pharmacy, \\ and pharmacy practice and Pharmacy $R$ and D Administration, Ministry of Health, Riyadh, KSA. \\ ${ }^{2}$ General Administration of Pharmaceutical Care, Ministry of Health, P.O.BOX 100, Riyadh 11392, Riyadh, KSA.
}

Received: 13 December 2017;

Accepted: 28 February 2018

*Correspondence to:

Dr. Yousef Ahmed Alomi, The Past General Manager of General Administration of Pharmaceutical Care, The Past Head, National Clinical pharmacy, and pharmacy practice, Head, Pharmacy $R$ and $D$ Administration, Ministry of Health, P.O.BOX 100, Riyadh 11392, Riyadh, Saudi Arabia.. Email:yalomi@gmail.com

Copyright: (1) the author(s),publisher and licensee Indian Academy of Pharmacists. This is an open-access article distributed under the terms of the Creative Commons Attribution Non-Commercial License, which permits unrestricted non-commercial use, distribution, and reproduction in any medium, provided the original work is properly cited.

\begin{abstract}
Objectives: The workforce of hospital pharmacist is one the elements of pharmacy strategic plan in Saudi Arabia. The purpose of this study is to explore hospital pharmacist's workforce at all healthcare organization in eleven years (2006-2016) in Saudi Arabia. Methods: It is a retrospective analysis of hospital pharmacist's workforce at all healthcare organization in the past eleven years in the period of 2006-2016 in Saudi Arabia. The analysis was carried out at nine working sectors; Ministry of Health Hospital, University Hospitals, Armed Forces Hospitals, National Gaud Hospitals, Security Forces hospitals, King Faisal Specialist hospital and research center, Royal Commission for Jubail and Yanbu Hospitals, Aramco Hospitals, and Privates hospitals. The analysis included hospital's distribution numbers, the pharmacist distribution numbers, and gender with nationality distribution across Saudi Arabia. Result: The total numbers of hospital were 452 with governments sectors was 311 (69\%) while 141 (31\%) of private Hospitals. The average numbers of hospitals were (423.45) with a range number of (384-467), and the total number was (467). The average numbers of hospital pharmacists were $(4,405.27)$ with a range number of $(3,315-6,559)$, and the total number was $(6,559)$. The total gender distribution of all hospital pharmacists included male 2,630.6 (59.72\%) and female $1,774.6(40.28 \%)$. The total nationality distribution of all hospital pharmacists was Saudi 2,449 (55.59\%) and non-Saudi 1,956.2 (44.41\%(. Of Saudi hospital pharmacists, 1,509.4 (61.64\%) was male, and 939.5 (38.36\%) was female. Conclusion: The number hospitals are tremendously increased over past years with an emphasis on $\mathrm{MOH}$ sector while the number of pharmacists not increased accordingly. The numbers of Saudi pharmacists at $\mathrm{MOH}$ hospital were more than other sectors while equal gender distributions. Targeting of Saudisitaion at all health sectors with non- $\mathrm{MOH}$ institutions is required.
\end{abstract}

Key words: Hospital Pharmacist, Workforce, Manpower, Ministry of Health, Saudi Arabia.

\section{INTRODUCTION}

There are several sectors provides healthcare services to all population in Saudi Arabia. The healthcare services provided through nine sectors. The Ministry of Health sector, privates sector, and seven non-MOH governmental sectors. ${ }^{[1]}$ The Ministry of Health coved almost sixty percent of our population while forty percent covered by non-MOH organizations and private sectors ${ }^{[1]}$ Every year the $\mathrm{MOH}$ published annual statistical book included all hospital pharmacists' workforces in all sectors. The book discussed the pharmacy workforces included nationalities, gender, working site, number of pharmacists and pharmacy technicians. Other of the description of workforces was missed. ${ }^{[1]}$ Also, several studies published and reported the pharmacy workforce for each sector in a different sector in-depth details. ${ }^{[2-13]}$ However, it is very hard to find a local study to compare all related sectors of pharmacy workforces, and Gulf and Middle East countries. The objective of this study is to explore the pharmaceutical care workforce at all healthcare hospitals providers in Kingdom of Saudi Arabia.

\section{METHODS}

It is a retrospective analysis of eleven years (2006-2016) of MOH hospital pharmacist workforce. All data were derived from Ministry of Health Statistical Year Books. ${ }^{[14-24]}$ It included pharmacist or clinical pharmacist's workforces at hospitals in Kingdom of Saudi Arabia. The type of hospital included having bed capacity of 50-1500 beds with Adults public hospitals, pediatrics and maternity hospitals, Psychiatric hospitals, Diabetic centers, Cardiology centers, Oncology Centers, Renal Dialysis Centers, and Medical cities. All Pharmacists worked at $\mathrm{MOH}$ administration or Hospitals or Primary care centers and non-MOH government hospitals including; University Hospitals, Armed Forces Hospitals, National Gaud Hospitals, Security Forces hospitals, King Faisal Specialist hospital and research center, Royal Commission for Jubail and Yanbu Hospitals, Aramco Hospitals, included in the studies. All private hospital included in the study. All community pharmacists or pharmacy technicians excluded from the study. All pharmacists expected to provide pharmaceutical according to ASHP definition and requirements. ${ }^{[1,25]}$ All type of pharmacy services were based on Saudi Central Board of hospital accreditation, a joint commission of hospital accreditation, ASHP best practice standards, and general administration of the pharmaceutical care strategic plan. ${ }^{[26-28]}$ All calculations were based on $\mathrm{MOH}$ workforce standards of hospitals. All calculation was done used Microsoft Excel version ten. The calculations were per each region for a total of twenty-one regions; hospital's distribution numbers, pharmacists' distribution numbers, the ratio of pharmacists per hospital, the gender distribution of Pharmacists per region, the gender distribution of Saudi Pharmacists per each region across Saudi Arabia. 


\section{RESULT}

The total numbers of hospitals were 452 hospitals in the kingdom of Saudi Arabia, 270 (59.73\%) Ministry of Health hospitals, 141 (31.19\%) private hospitals, and $41(9.08 \%)$ non-MOH governmental hospitals. Over the eleven years, the average number of hospitals were (423.45) with a range number of (384-467), and the total number was (467) as explored in Table 1 and 2. The average numbers of hospital pharmacists were $(4,405.27)$ with a range number of $(3,315-6,559)$, and the total number was $(6,559)$. The highest sector had an average numbers of hospital pharmacists were Ministry of health $(1,625)$ followed by Private hospitals $(1,225.10)$ and Armed Forces Hospitals sector (550.18) pharmacists as explore in Table 3. The total gender distribution of all hospital pharmacists included male 2,630.6 (59.72\%) and female $1,774.6(40.28 \%)$. The total nationality distribution of all hospital pharmacists was Saudi 2,449 (55.59\%) and non-Saudi 1,956.2 (44.41\%(. Of Saudi hospital pharmacists, 1,509.4 (61.64\%) were male, and $939.5(38.36 \%)$ were female as explored in Table 4, 5 and 6.

\section{DISCUSSION}

The healthcare care organization consisted of several sections including $\mathrm{MOH}$ institution, non- $\mathrm{MOH}$ institutions including universities hospitals, Military hospitals, National Guard hospitals, King Faisal Specialist and Research Center, Juba and Yunbu institution, and private hospitals. The $\mathrm{MOH}$ established healthcare staff requirements for hospitals and primary care centers including pharmacy services. The staff requirements based on bed capacity for instance physician one per bed and the pharmacy equal to 0.2 pharmacists per bed. ${ }^{[29]}$ The system of the $\mathrm{MOH}$ can calculation the requirements of healthcare staff financially. The annual budget for each hospital distributed based on the requirements standard. Over past years, several hospitals from each sector founded to provide healthcare to the patients in Kingdom of Saudi Arabia. The actual comparisons of workforce of pharmacy yet does not exist. The author tried to explore the pharmacy workforce for all sectors without community pharmacist due to the missed data of $\mathrm{MOH}$ year statistical book. The finding showed significant variation between all sectors for instant the $\mathrm{MOH}$ hospitals and privates hospitals, very high incremental over the past years while the other sectors not increased much looks like them. Despite the increased hospital's numbers, the number of pharmacists not increased in equal percentages as a comparison with the non-MOH number of the hospital almost stagnant while the number of pharmacists increased on annually. The total number of the pharmacists were lower that's what found by others. ${ }^{[2,7,8]}$ The demands for pharmacists were high, and a number of the college of pharmacies were low over that past years. The average gender distribution found almost more male pharmacists than female even with Saudi pharmacist; it looked like what founded with Hawthorne, $\mathrm{N}$ et al. and Gaither, CA. et al. ${ }^{[7,11]}$ While it was lower than in female pharmacists what founded by Gal, D et al. in Europe, Western Pacific, Eastern Mediterranean countries, and that is related to the newest graduated pharmacists were male. ${ }^{[8]}$ The common nationality among all sectors, almost fifty percent distributed of Saudi and Non-Saudi. Also, the Saudi pharmacists were mostly founded in $\mathrm{MOH}$ hospital while non-Saudi pharmacists were founded in private hospitals. The significant differences related to the pharmacist wish in the governmental sector more than private sectors due to the significant differences in salary and workload. Also the private wished to recruit non-Saudi pharmacy technician better than Non-Saudi pharmacist due to the lower salary. Others parameters of pharmacy workforces could not compare with studies because it missed at $\mathrm{MOH}$ statistical books. The number of pharmacists should increase at $\mathrm{MOH}$ hospitals and private organization with the emphasis of Saudization of the pharmacist in private's hospitals. 


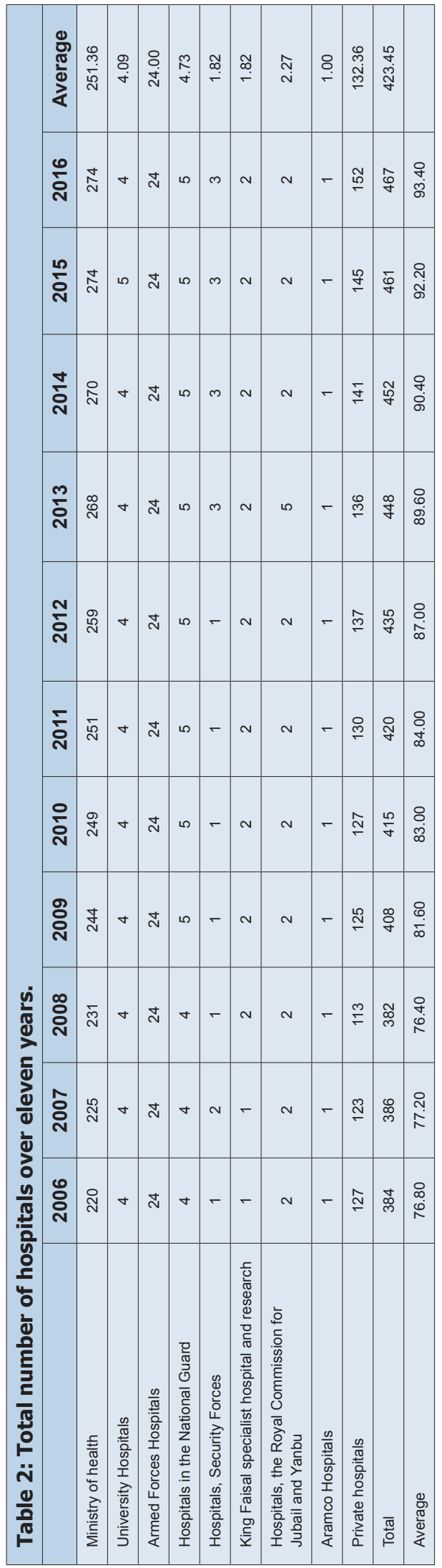

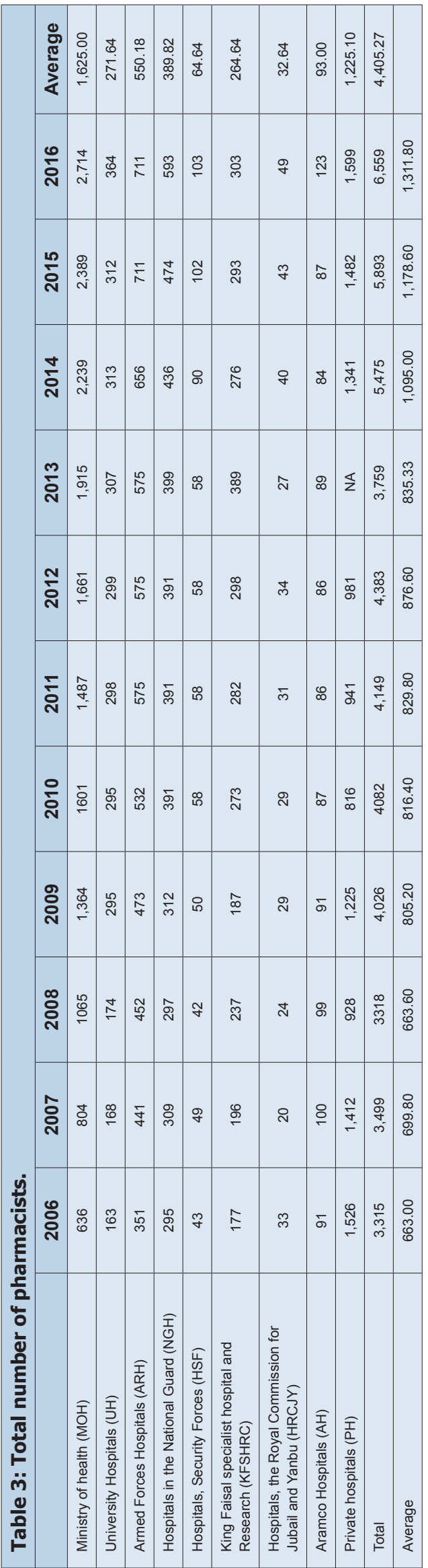




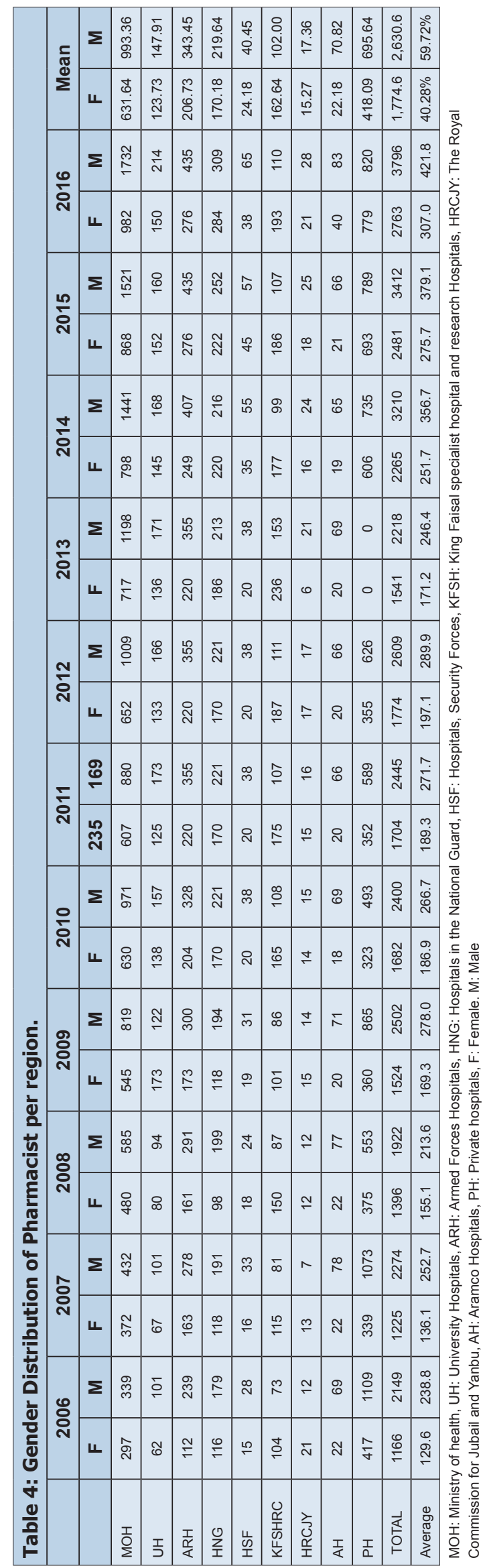

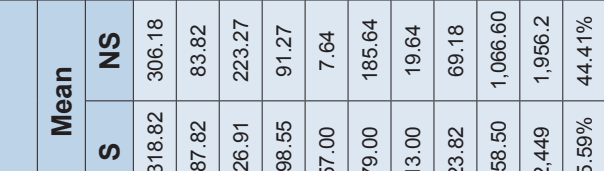

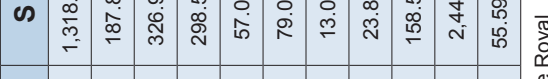

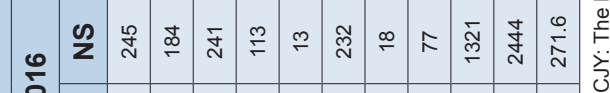

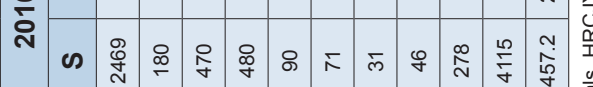

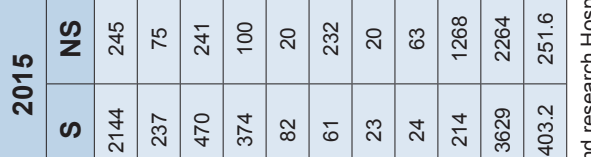

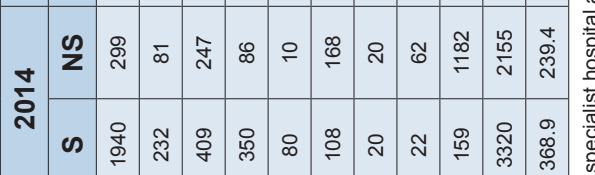

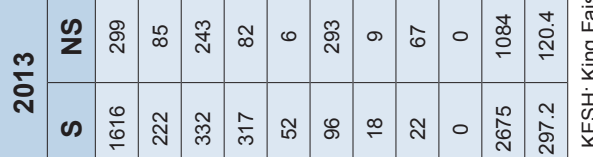

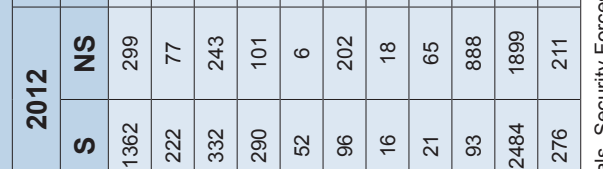

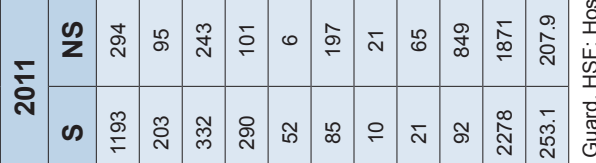

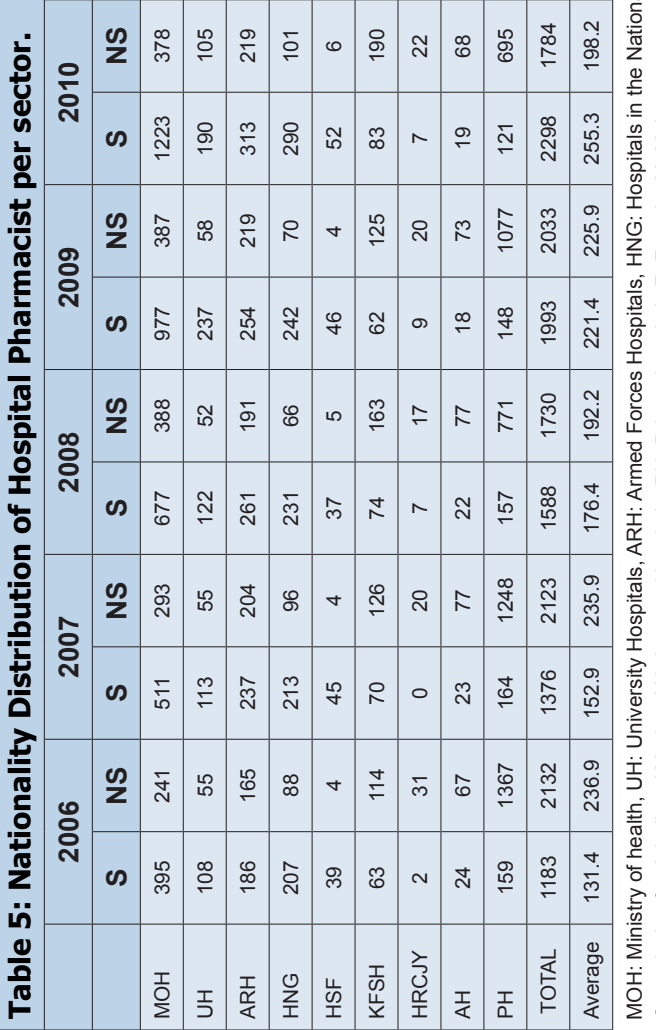




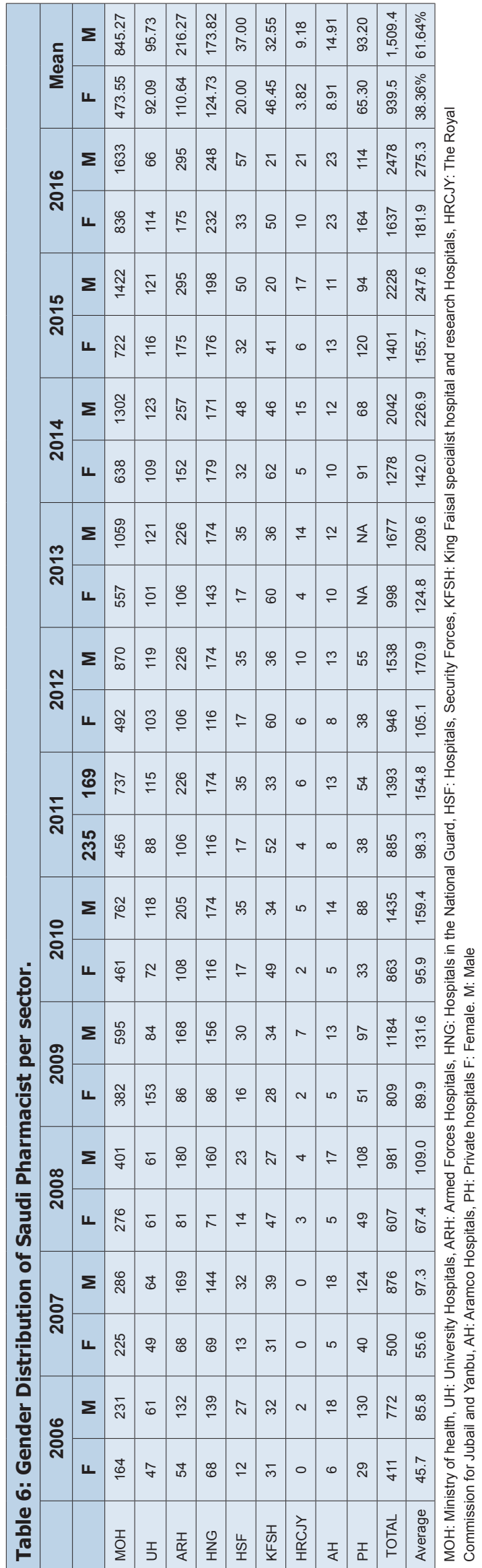

\section{CONCLUSION}

After revision of the past eleven years, there was much expanded of Ministry of health and private's hospitals while poor increasing of a number of a pharmacist. Non-MOH governmental hospital not expanded much with an excellent number of pharmacists. The Saudization application was deficient in the private sector, King Faisal Specialist hospital and Armco hospitals. Targeting of increasing number of pharmacist with complete Saudization is required at $\mathrm{MOH}$, and private hospitals to meet the demand for pharmacy services and reach better patient condition outcomes and increased the patient satisfaction of pharmaceutical care services in all sectors in Kingdom of Saudi Arabia.

\section{ACKNOWLEDGEMENT}

None.

\section{CONFLICT OF INTEREST}

None.

\section{ABBREVIATION USED}

KSA: Kingdom of Saudi Arabia; MOH: Ministry of Health;

\section{REFERENCES}

1. American Society of Hospital Pharmacists. ASHP Statement on Pharmaceutical Care. Am J Hosp Pharm. 1993;50:1720-3.

2. Mcleod DC. Contrast in Pharmacy Manpower Planning between the United States and Northen European Countries. Drug Intell Clin Pharm. 1986;20:210-2.

3. HRSA. A study of the supply and demand for pharmacists. Department of Health and Human Services. 2000;100. Available from: www.fip.org/humanresource.

4. Bond CA, Raehl CL, Patry R. Evidence-based core clinical pharmacy services in United States hospitals in 2020: services and staffing. Pharmacotherapy. 2004;24(4):427-40.

5. Bond CA, Raehl CL. Clinical pharmacy services, pharmacy staffing, and adverse drug reactions in United States hospitals. Pharmacotherapy. 2006;26(6):735-47.

6. Bond CA, Raehl CL. Clinical pharmacy services, pharmacy staffing, and hospital mortality rates. Pharmacotherapy. 2007;27(4):481-93.

7. Hawthorne N, Anderson C. The global pharmacy workforce: a systematic review of the literature. Hum Resour Health. 2009;7(1):48.

8. Gal D, Bates I. 2012 FIP Global Pharmacy Workforce Report. 2012. Available from: www.fip.org/humanresource

9. Workforce H. Pharmacist Workforce. 2012-Provincial / Territorial Highlights. 2012.

10. Health Workforce Australia. Australia's Health Workforce Series: Pharmacists in Focus. 2014:1-47.

11. Gaither CA, Schommer JC, Doucette WR, Kreling DH, Mott DA. 2014 National Pharmacist Workforce Survey. Workforce. 2015. Available from: http://www. pharmacy.wsu.edu/information/2009.Pharmacist.Workforce.Survey.pdf.

12. Robinson E, Shcherbakova N. Assessment of Pharmacy Manpower and Services in New England. J Pharm Pract. 2016;29(6):549-55.

13. Pedersen CA, Schneider PJ, Scheckelhoff DJ. ASHP national survey of pharmacy practice in hospital settings: Dispensing and administration - 2014. Am J Heal Pharm. 2015;72:1119-37.

14. Health Statistical Year Book. Saudi Ministry of Health; 2006. Available from: http:// www.moh.gov.sa/en/Ministry/Statistics/book/Pages/default.aspx.

15. Health Statistical Year Book. Saudi Ministry of Health; 2007. Available from: http:// www.moh.gov.sa/en/Ministry/Statistics/book/Pages/default.aspx.

16. Health Statistical Year Book. Saudi Ministry of Health; 2008. Available from: http:// www.moh.gov.sa/en/Ministry/Statistics/book/Pages/default.aspx.

17. Health Statistical Year Book. Saudi Ministry of Health; 2009. Available from: http:// www.moh.gov.sa/en/Ministry/Statistics/book/Pages/default.aspx.

18. Health Statistical Year Book 2010. Saudi Ministry of Health; 2010. Available from: http://www.moh.gov.sa/en/Ministry/Statistics/book/Pages/default.aspx.

19. Health Statistical Year Book. Saudi Ministry of Health; 2011. Available from: http:// www.moh.gov.sa/en/Ministry/Statistics/book/Pages/default.aspx. 


\section{Alomi, et al.: Past one-decade Hospital Pharmacists Workforce analysis in Saudi Arabia}

20. Health Statistical Year Book. Saudi Ministry of Health; 2012. Available from: http:// www.moh.gov.sa/en/Ministry/Statistics/book/Pages/default.aspx.

21. Health Statistical Year Book 2013. Saudi Ministry of Health; 2013. Available from: http://www.moh.gov.sa/en/Ministry/Statistics/book/Pages/default.aspx.

22. Health Statistical Year Book. Saudi Ministry of Health; 2014. Available from: http:// www.moh.gov.sa/en/Ministry/Statistics/book/Pages/default.aspx.

23. Health Statistical Year Book 2015. Saudi Ministry of Health; 2015. Available from: http://www.moh.gov.sa/en/Ministry/Statistics/book/Pages/default.aspx.

24. Health Statistical Year Book 2016. Saudi Ministry of Health; 2016. Available from: http://www.moh.gov.sa/en/Ministry/Statistics/book/Pages/default.aspx.
25. American Society of Hospital Pharmacists. ASHP Guidelines on a Standardized Method for Pharmaceutical Care. Am Soc Heal Pharm. 1996;53(14):1713-6.

26. Medication Management (MM). In: National Hospital Standards. 2nd Editio. Saudi Central Board for Accreditation of Healthcare Institutions. 2015;194-211.

27. Comprehensive Accreditation Manuals. Joint Commission Resources. Available from: http://www.jcrinc.com/store/publications/manuals/

28. Alomi YA, Alghamdi SJ, Alattyh RA. Strategic Plan of General Administration of Pharmaceutical Care at Ministry of Health in Saudi Arabia 2012-2022. J Pharm Pharm Sci. 2015;1(3):1-8.

29. Alomi YA, Ahmed Alomi Y, Pharm B, Clin Pharm M. A new Guidelines on Hospital Pharmacy Manpower in Saudi Arabia. J Pharm Pract Community Med. 2016;2(2).

Cite this article as: Alomi YA, Alghamdi SJ, Alattyh RA. Hospital Pharmacist Workforce Analysis in Eleven-Year 2006-2016 at Healthcare Institutions in Saudi Arabia. J Pharm Pract Community Med. 2018;4(1s):S103-S8. 